\title{
Microsurgical Treatment of Brain Arteriovenous Malformations in Sub-Saharan Africa, About a Series of 14 Patients Treated in Senegal
} \author{
Ba and Seydou Boubakar Badiane \\ Neurosurgery Department, Fann Teaching Hospital, Senegal \\ *Corresponding author: Mbaye Thioub, Address: Neurosurgery Department, Fann Teaching Hospital, Dakar, Senegal \\ Submission: November 11, 2017: Published: January 30, 2018
}

Mbaye Thioub*, Maguette Mbaye, Alioune Badar Thiam, El Hassimi Cisse, Cheikh Sy, Ndaraw Ndoye, Momar Codé

\begin{abstract}
Brain Arteriovenous malformations are difficult lesions to manage surgically. In sub-Saharan Africa the lack of adequate medical equipment make them more challenging because surgery remains the only option. The aim of this report is to demonstrate the results of microsurgical treatment of $b$ AVMS in these less than ideal conditions.

Methods: We reviewed retrospectively 14 consecutive cases of b AVMs operated on in Senegal. Patient characteristics, radiological data and outcomes have been analysed.

Results: There were 29 cases of bAVMs that were received in our department in the 3 year period, and among those, there were 14 cases for which operations were performed. The patient ages ranged from 7 to 64 years (mean age: 37.6 years). Ten patients were male and 4 were female. Twelve patients presented with ruptured AVM. The mean AVM size was $3.6 \mathrm{~cm}$. According to Spetzler-Martin grade, 5 AVM were I, 6 were II, 2 were III and one was grade IV. No intranidal aneurysm was found. Two patients died preoperatively. According to mRS, for the 12 patients available to follow-up, 9 patients had good outcome (mRS 0 to 2) and 3 patients had poor outcome (mRS 3 and 4).
\end{abstract}

Conclusion: In sub-Saharan Africa this pathology is even more difficult to manage due to under-equipment conditions but judicious selection of patients and the surgical strategy are secrets for good results.

Keywords: Subsaharan Africa; bAVMS; Microsurgery

\section{Introduction}

Brain arteriovenous malformations (bAVMs) consist of abnormal tangles of dilated vascular structure called nidus, which connects arteries and veins directly without intervening capillary beds. It is classically believed that bAVMs are "congenital" lesions. Brain AVMs are relatively uncommon with a prevalence $<1 \%$ and an incidence between 0.01 and $0.001 \%$ [1-4]. AVMs account for $1 \%$ to $2 \%$ of all strokes, $3 \%$ of strokes in young adults, and $9 \%$ subarachnoid hemorrhages, and response for $4 \%$ of all primary intracerebral hemorrhages $[5,6]$.

Their treatment including microsurgical resections, radiotherapy and endovascular embolization has made great advance over the past decades, but remains challenging and controversial with a high rate of procedure related complications [7-10].

In sub-Saharan Africa the management of these malformations is made even more difficult by the lack of means of diagnosis and treatment. Indeed, arteriography remains unavailable in almost all the countries of this region. Therefore, surgery remains the only option available for the treatment of AVM. The objective of this study is to present the conditions of AVM management in this context and to evaluate the therapeutic results through a retrospective series of 14 patients operated on in Dakar between May 2013 and December 2016.

\section{Patients and Methods}

We analysed retrospectively 14 consecutive cases of b AVMs operated on between May 2013 and December 2016 in Neurosurgical Department of Fann Hospital. For each patient we have listed the data such as age, sex, and medical history. Neurological status at admission was assessed using clinical data and GCS (Glasgow coma scale). The time for admission and diagnosis was notified. Intracerebral haemorrhage was assessed using the CT scan results. CT angiography and MRA were used for radiological confirmation of AVM. The Spetzler-Martin grading [11] was used to classify the malformations. After operation all patients are directly admitted in our dedicated ICU. For each patient angio 
CT was done postoperatively to assess AVM removal. Outcomes are reported using the modified Rankin Scale (mRS) [12], with a score of 0 to 2 indicating good neurological outcome, 3 to 5 indicating poor outcome, and 6 indicating death. The mean follow up period was 28 months.

Results

\section{Patient and AVM characteristics (Table 1)}

Table1: Characteristics of all patients.

\begin{tabular}{|c|c|c|}
\hline Parameter & Variables & Patients No \\
\hline \multirow{3}{*}{ Sex } & Male & 10 \\
\cline { 2 - 3 } & Female & 4 \\
\hline \multirow{3}{*}{ Age } & Mean : 37.6 & \\
\cline { 2 - 3 } & Range : [7-64] & \\
\hline \multirow{3}{*}{ Presentation } & Haemorrhage & 12 \\
\cline { 2 - 3 } & Seizure & 02 \\
\cline { 2 - 3 } & Incidental & 0 \\
\hline \multirow{5}{*}{ Location } & Frontal & 7 \\
\cline { 2 - 3 } & Temporal & 3 \\
\cline { 2 - 3 } & Parietal & 2 \\
\cline { 2 - 3 } & Occipital & 1 \\
\cline { 2 - 3 } & Cerebellar & 1 \\
\hline
\end{tabular}

There were 29 cases of bAVMs that were received in our department in the 3 year period, and among those, there were 14 cases for which operations were performed. The patient ages ranged from 7 to 64 years (mean age: 37.6 years). For patients were less than 18 years of age at the time of diagnosis. According to gender, 10 patients were male and 4 were female. Twelve patients presented with ruptured AVM. The average admission period was 3.7 days after the onset of hemorrhage (with a range of 1 day to 6 days). Clinical presentations at the time of admission were as follows.

\section{Illustrative case (Figure 1)}
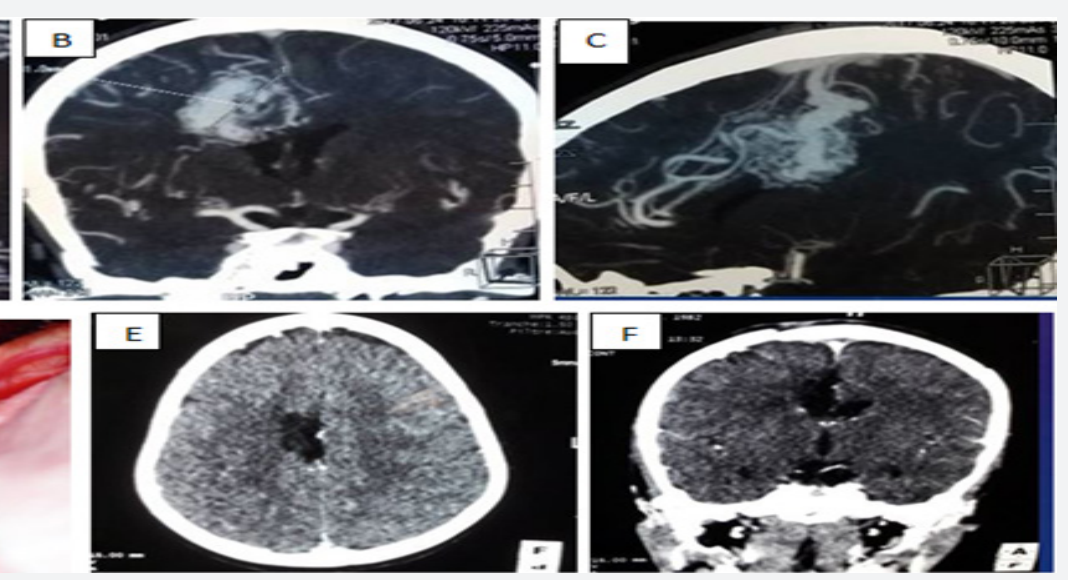

Figure 1: Pre, Intra and post operative images from the Illustrative case.

A, B, C: Axial, Coronal and sagittal views on Angio CT demonstrating this right Medial frontal AVM with feeders from pericallosal, callosamarginal and lenticulostriated arteries; Note big draining veins superiorly into superior sagittal sinus.

D: Intraoperative view showing interhemispheric approach from the contralateral side and the nidus after opening of the falx.

E, F: Post-operative images showing complete removal of the AVM. 
A 15-year-old boy was diagnosed with a right medial frontal AVM on CT angiography. He was admitted for minor head trauma (He was beaten by one of his playmates) with loss of counsciousness. He had a Glasgow coma scale of 13 and discreet left hemiparesis. The CT scan showed an intraventricular hemorrhage. It seemed difficult to relate this hemorrhage to his trauma. So a CT angiography was done that revealed this medial frontal AVM (Figure 1A-1C). The imaging demonstrated feeders from pericallosal, calloso-marginal and lenticulostriated arteries. Venous draining was superior into the superior sagittal sinus. Embolization being unavailable we decided to operate the AVM through a contralateral anterior interhemispheric approach two weeks after the onset of the bleeding.

\section{Surgical procedure}

After exposition of the interhemispheric fissure (Figure 1D) by the left side we opened the falx widely and made a dissection plan around the AVM. The feeders were cut allowing the nidus to be pulled into the interhemispheric space. The draining veins were divided and the nidus removed. Post operatively he presented a transient worsening of his motor deficit but he recovered completely after two weeks. The post operative CT angiography showed a complete removal of the AVM (figure1 E,F). At the last follow-up he was neurologically intact.

\section{Discussion}

bAVMs are congenital and sporadic lesions, but some have apparently genetic backgrounds. Their molecular and histopathological analysis revealed the higher level of angiogenic factors and inflammatory cytokines. Minor trauma, ischemia, venous hypertension, exogeneous growth factor delivery, high endogenous angiogenic factors, inflammation, and infection are known angiogenic factors contributing to manifest bAVMs. There is actually no medical treatment available to prevent development or rupture of bAVMs [13].

Judicious selection of patients for treatment requires carefully balancing treatment complications against the risk of hemorrhage in the natural history course. The overall risk of hemorrhage is $2 \%-4 \%$ per year, but varies widely depending on the number of risk factors a patient carries. The rate of hemorrhage in unruptured patients is around 2\% per year. Previous hemorrhage is the strongest and most reproducible risk factor for subsequent hemorrhage in almost all AVM natural history studies, whereas angiographic factors, such as deep venous drainage pattern, and deep or infratentorial AVM location [14]. This study describes a preliminary surgical experience with 14 AVMs treated in a developing country of Africa. We admitted in this 3 years period 29 AVMs and 14 of them were operated. The surgical population of our study consisted of 10 male and 4 female. It is a very low incidence if one considers the population of the country (15 millions). Previous reports in subSaharan Africa showed this point $[15,16]$. In the global published literature, the incidence of intracranial AVMs is $1 \pm 1.4$ cases per 100,000 person-years and both sexes are affected equally [9]. This low rate of AVMs is probably due to the lack of diagnosis tools in our country. MRI is not easily available to all patients and most of the non ruptured AVMs are probably not diagnosed.

Regarding to diagnosis, we do not have arteriography in our country. Although CT angiography and MRI can confidently confirm the diagnosis of AVM, the assessment of dynamic character can only be made by arteriography. Thus it is difficult for us to appreciate the speed of the flow, the existence or not of intranidal aneurysms. These elements must be taken into consideration in the therapeutic strategy to limit the per-operative difficulties. In addition arteriography may offer the possibility of preoperative embolization. This procedure reduces intraoperative blood loss during AVM surgical resection and may improve the safety of these procedures by potentially decreasing the technical difficulty of resection and operative duration [17].

The grading systems (Spetzler, supplementary grading) are useful tools in the management of AVM. They are good predictors for surgical risk; they simplify complex decisions and guide patient selection [2,11]. It is recognized that Spetzler AVMs Grade I and II can be operated without significant risk from a functional point of view. Grades III and IV are most often observed or treated by other modalities such as embolization and radiosurgery.

If the treatment of unruptured AVM is subject to great controversy, the indication to eradicate a ruptured AVM is accepted by all even ifthere are many controversies in reported outcomes [18]. However the precise analysis of the risks related to the procedure is necessary to avoid dramatic neurological complications.

Definitely the judiscious patient selection is the secret to good results. The ARUBA trial showed that medical management alone is superior to medical management with interventional therapy for the prevention of death or stroke in patients with unruptured brain arteriovenous malformations [3]. These risks related to the treatment of AVM should not be neglected. In our study we operated only half of the diagnosed AVMs (14/29). The others were either unruptured or too high grades of Spetzler-Martin. Ren et al. [9] presented a cohort comprising 445 patients treated with microsurgical resections in a large single center, and illustrated a permanent postoperative morbidity of $14.8 \%$ and a mortality of $7.9 \%$ [9].

Beijnum et al. [19] have already reported 7\% of poor outcomes (death or permanent neurological disabilities) after microsurgical obliteration of AVM [19]. In our series, five patients (35\%) had poor outcomes. But 3 of them had poor neurological status at the admission. One of these patients had a ruptured cerebellar AVM with coma. It's a difficult location for microsurgery. Patients with cerebellar AVMs are significantly more likely to present with hemorrhage than patients with cerebral AVMs, resulting in more neurological deficits preoperatively [20,21].

\section{Conclusion}

bAVMs are one of the most challenging lesions for neurosurgeons. Their treatment requires an undeniable learning curve for the neurosurgeon beside a well-equipped medical 
environment. The judicious selection of patients and the surgical strategy are secrets for good results. In sub-Saharan Africa this pathology is even more difficult to manage due to under-equipment conditions but the results of this series are encouraging despite its small size.

\section{Conflicts of Interest}

The authors have declared that no conflicts of interest exist.

\section{References}

1. Laakso A, Hernesniemi J (2012) Arteriovenous malformations: epidemiology and clinical presentation. Neurosurg Clin N Am 23(1): $1-6$.

2. Lawton MT, Kim H, McCulloch CE, Mikhak B, Young WL (2010) A supplementary grading scale for selecting patients with brain arteriovenous malformations for surgery. Neurosurgery 66(4): 702-713.

3. Mohr JP, Parides MK, Stapf C, Moquete E, Moy CS (2014) Medical management with or without interventional therapy for unruptured brain arteriovenous malformations (ARUBA): a multicentre, nonblinded, randomised trial. Lancet 383(9917): 614-621.

4. Ondra SL, Troupp H, George ED, Schwab K (1990) The natural history of symptomatic arteriovenous malformations of the brain: a 24-year follow-up assessment. J Neurosurg 73(3): 387-391.

5. Al-Shahi R, Warlow C (2001) A systematic review of the frequency and prognosis of arteriovenous malformations of the brain in adults. Brain 124 (10): 1900-1926.

6. Conger A, Kulwin C, Lawton MT, Cohen-Gadol AA (2015) Endovascular and microsurgical treatment of cerebral arteriovenous malformations: Current recommendations. Surgical Neurology International 6: 39.

7. Bendok BR, El Tecle NE, El Ahmadieh TY, Koht A, Gallagher TA, et al. (2014) Advances and innovationsin brain arteriovenous malformation surgery. Neurosurgery 74 Suppl 1: S60-S73.

8. Plasencia AR, Santillan A (2012) Embolization and radiosurgery for arteriovenous malformations. Surg Neurol Int 3(Suppl 2): 90-104.

9. Ren Q, He M, Zeng Y, Liu Z, Liu H, Xu J (2017) Microsurgery for intracranial arteriovenous malformations: Long-term outcomes in 445 patients. PLoS ONE 12(3): e0174325
10. Rubin BA, Brunswick A, Riina H, Kondziolka D (2014) Advances in radiosurgery for arteriovenous malformations of the brain. Neurosurgery 74 Suppl 1: 50-59.

11. Spetzler RF, Martin NA (1986) A proposed grading system for arteriovenous malformations. J Neurosurg 65(4): 476-483.

12. Bonita R, Beaglehole R (1988) Modification of Rankin Scale: Recovery of motor function after stroke. Stroke 19(12): 1497-1500.

13. Komiyama M (2016) Pathogenesis of Brain Arteriovenous Malformations. Neurol Med Chir (Tokyo) 56(6): 317-325

14. Rutledge WC, Ko NU, Lawton MT, Kim H (2014) Hemorrhage Rates and Risk Factors in the Natural History Course of Brain Arteriovenous Malformations. Transl Stroke Res 5(5): 538-542.

15. Gueye M, Kone S, Kabre A, Badiane SB, Sakho Y, Ndiaye IP (2014) Anévrysmes artériels et malformations artério-veineuses cérébrales. A propos de 60 cas opérés à la clinique neurochirurgicale du centre Hospitalo-Universitaire de Dakar. Afri J Neurol/ sci/ 7: 31-35,

16. Ruberti RF (1993) Surgical treatment of cerebral supratentorial arteriovenous malformations. Afri J Neurol/ sci/ 12: 1-5.

17. Conger JR, Ding D, Raper DM, Starke RM, Durst CR (2016) Preoperative Embolization of Cerebral Arteriovenous Malformations with Silk Suture and Particles: Technical Considerations and Outcomes J Cerebrovasc Endovasc Neurosurg 18(2): 90-99.

18. Sackey FA, Pinsker NR, Baako BN (2017) Highlights on Cerebral Arteriovenous Malformation Treatment Using Combined Embolization and Stereotactic Radiosurgery: Why Outcomes are Controversial? Cureus 9(5): e1266.

19. Van Beijnum J, Van der Worp HB, Buis DR, Al-Shahi Salman R, Kappelle LJ, et al. (2011) Treatment of brain arteriovenous malformations: a systematic review and meta-analysis. JAMA 306(18): 2011-2019.

20. Rodríguez-Hernández A, Kim H, Pourmohamad T, Young WL, Lawton MT, et al. (2012) Cerebellar Arteriovenous Malformations: Anatomical Subtypes, Surgical Results, and Increased Predictive Accuracy of the Supplementary Grading System. Neurosurgery 71(6): 1111-1124.

21. Potts MB, Lau D, Abla AA, Kim H, Young WL (2015) Current surgical results with low-grade arteriovenous malformations. J Neurosurg 122(4): 912-920. 